\title{
THINKING SPATIALLY, ACTING COLLABORATIVELY A GIS-based Health Decision Support System for Improving the Collaborative Health-planning Practice
}

\author{
Ori Gudes \\ School of Urban Development, Queensland University of Technology, 2 George Street, Brisbane, Australia \\ ori.gudes@student.qut.edu.au \\ Griffith Health Institute, Griffith University, University Drive, Meadowbrook , Australia \\ o.gudes@griffith.edu.au \\ Virendra Pathak \\ School of Urban Development, Queensland University of Technology, 2 George Street, Brisbane, Australia \\ virendra.pathak@qut.edu.au \\ Elizabeth Kendall \\ Griffith Health Institute, Griffith University, University Drive, Meadowbrook , Australia \\ e.kendall@griffith.edu.au \\ Tan Yigitcanlar \\ School of Urban Development, Queensland University of Technology, 2 George Street, Brisbane, Australia \\ tan.yigitcanlar@qut.edu.au
}

Keywords: $\quad$ Spatial Health Decision Support Systems, Collaborative Health Planning, DSS, E-Health

Abstract: The field of collaborative health planning faces significant challenges due to the lack of effective information, systems and the absence of a framework to make informed decisions. These challenges have been magnified by the rise of the healthy cities movement, consequently, there have been more frequent calls for localised, collaborative and evidence-driven decision-making. Some studies in the past have reported that the use of decision support systems (DSS) for planning healthy cities may lead to: increase collaboration between stakeholders and the general public, improve the accuracy and quality of the decision-making processes and improve the availability of data and information for health decision-makers. These links have not yet been fully tested and only a handful of studies have evaluated the impact of DSS on stakeholders, policy-makers and health planners. This study suggests a framework for developing healthy cities and introduces an online Geographic Information Systems (GIS)-based DSS for improving the collaborative health planning. It also presents preliminary findings of an ongoing case study conducted in the Logan-Beaudesert region of Queensland, Australia. These findings highlight the perceptions of decisionmaking prior to the implementation of the DSS intervention. Further, the findings help us to understand the potential role of the DSS to improve collaborative health planning practice. 


\section{INTRODUCTION}

In recent years, a model of planning known as the 'Collaborative health planning' has evolved to become one of the key foundations of contemporary health planning. This model is grounded in both 'communicative planning theory' and 'population health theory' (Gudes et al. 2010). Growing evidence from the literature shows that large health systems seeking to create collaborative health planning projects face many planning challenges, including engaging multiple stakeholder groups; making consensus-based decisions; bringing evidence into the decision-making processes; planning in a participatory manner; and exploring the full spectrum of health determinants based on diverse sources of information.

For this reason, Northridge et al. (2003) argued that stronger collaborations were needed between urban planners, health policy-makers, and community members to ensure effective planning in the light of 'Healthy Cities (WHO, 1999)' initiative. It is recognised that evidence-based decision making is critical to the collaborative planning process and the evidence-based approach is based on an effective access to data. It was noted that the smart use of data and publicly available information on health is essential to generate informed decision-making (NHHRC, 2009). Literature has suggested that increasing and improving access to relevant data may lead to an improved decision-making processes. Thus, there is a need to develop a framework for stakeholders to support them to access relevant data.

Some studies have justified the use of decision support systems (DSS) in planning for healthy cities as these systems have been found to improve the planning process (Cromley \& McLafferty 2003). These systems have been gaining prominence in recent years and have been described by several researchers over the last few decades as an efficient support tool for health planning (Reinke 1972; Reeves \& Coile 1989; Higgs \& Gould 2001). However, knowledge about the impact of DSS on health planners is relatively limited. This study provides a framework for organising and delivering information to planners to use in developing healthy cities. It also introduces an online Geographic Information Systems (GIS)-based DSS, developed for improving the collaborative health planning. To ascertain whether the DSS has a valuable impact on health planners, a study is currently being conducted in the Logan-Beaudesert Health Coalition (LBHC). This paper provides an overview of the healthy cities movement and collaborative health planning, introduces ICT and E-Health approaches and the DSS. It then discusses a proposed framework for organising information that can contribute to collaborative health planning. Preliminary results are presented to demonstrate the perceptions of decisionmaking within the LBHC and the potential role of the DSS.

\section{THE HEALTHY CITIES \& COLLABORATIVE HEALTH PLANNING}

The 'Healthy Cities' initiative was officially introduced in 1986 by Ilona Kickbusch at a conference of the World Health Organisation (WHO) in Copenhagen, Denmark. To date, "about 90 cities are members of the WHO European Healthy Cities Network, and 30 national Healthy Cities networks across the WHO European Region have more than 1400 cities and towns as members"(WHO, 2010). Also, according to Health Cities Illawarra (2010), "since 1985 over 3000 healthy cities, towns, villages and islands have been established throughout the world". In order to plan effectively for healthy cities, the historic collaboration between urban planning and public health professionals must be revived, and this collaboration must be based on informed evidence-based decision-making (Northridge et al., 2003). However, evidence-based decision-making has been hindered by the fact that there are no models to define the type of information that must be considered by health planners and there is no method for sharing this information in a meaningful form. As Flynn (1996) concluded, every community is unique, with different physical, social, political and cultural contexts that must be understood in the planning process. Therefore, it is necessary for planners to develop a thorough understanding of each individual community health profile and its features that influence health. Schulz and Northridge (2004) developed a public health framework for health impact assessments. This framework summarises the different levels of factors that impact upon health and, therefore, should be considered in health planning. According to Northridge et al. (2003), factors that contribute to health can be divided into four levels, namely: Macro, Meso, Micro and Individual. According to the model, these factors interact to contribute to health in the community, so 
must all be considered when undertaking health planning.

Some evidence in the literature supports the application of collaborative health planning within the healthy cities approach. First, and broadly, collaborative planning promotes democratic decision-making that facilitates shared ownership and engagement in solutions (Murray 2006). Murray has also suggested a model to evaluate the level of collaboration in planning. The model identifies different levels of collaboration (i.e. Networking, Cooperation, Coordination, Coalition and Collaboration) that might be applied. Additionally, he highlighted the following domains of decisionmaking that define collaborative health planning: Evidence-based decision-making; Perceived consensus; Participation in decision-making; and Perceived satisfaction of decision-making. Second, it encourages planners to communicate, interact and negotiate with other sectors in order to resolve disputes between groups that may have some investment in the planning process (Campbell \& Fainstein 1996). Third, it facilitates a more collaborative form of governance which in turn implies a more collaborative and efficient delivery of services to the community(Bishop \& Davis 2001). Therefore, collaborative health planning has the potential to become a fundamental approach to planning.

\section{ICT AND E-HEALTH APPROACHES}

The World Health Organisation (WHO) defines E-health as 'the cost-effective and secure use of information and communications technologies in support of health-related fields, including healthcare services, health surveillance, health literature, and health education, knowledge and research'. The literature has highlighted the benefits of using Ehealth and ICT tools to obtain better understanding of health planning for policy-makers. Amongst these some prospective benefits are: increased access to healthcare services and health-related information, improved ability to diagnose and track diseases, more actionable public health information and expanded access to ongoing medical education and training for health practitioners (Wave, 2009). The National Electronic Decision Support Taskforce (2008) has also emphasised that EDSS (Electronic DSS) are essential components of designing a national e-health strategy.
Conversely, only little research has been focused on the potential of E-health environments and ICT tools to alleviate the negative health consequences of social determinants of health (Han et al., 2010). As the awareness to the importance of broad understanding of social determinants of health grows, it would be crucial to evaluate the impact of ICT tools and E-health initiatives leveraging health planners and decision-makers knowledge. Thus, ICT tools and E-health initiatives should be focused on finding innovative ways to enhance the day-to-day work efficiency of health planners.

One of the innovative ways to present, store, analyse and manipulate information is by adding its spatial aspect. Particularly, given that social determinants of health are spatially oriented. In this regard, E-health initiatives may provide new standards of accessibility to spatial health data. For instance, health information could be geocoded and displayed spatially, so end-users can create maps by using different layers of spatial information overlaid each other. Further, spatial analysis can be applied by mapping layers of socio-economics, demographics, and projected regional growth forecasts, thus providing a new way of looking at health concerns. Thus, application of spatial technologies is an important step towards a better understanding of public health issues and their inherent complexities and for gaining insight into the spatial distribution of health determinants (Higgs \& Gould, 2001). However, it is essential to expand the use of this tool through online ICT platforms or as part of broader E-health initiatives, to support health decision-making processes.

\section{A FRAMEWORK FOR COLLABORATIVE HEALTH-PLANNING}

The overall aim of decision support systems (DSS), without substituting decision-makers, is to improve the efficiency of the decisions made by stakeholders, optimising their overall performance and minimising judgemental biases (Turban 1993). A framework has been proposed for collaborative health planning that illustrates the overall place of DSS within a healthy cities' planning initiative (See Appendix). However, it is imperative that the DSS be based on a broad information framework. Specifically, it is suggested that the Information Management Framework based on Schulz and 
Northridge (2004) should guide the development of a community health profile, with information being derived from multiple sources. The ability to present this information in meaningful, accessible and usable ways is a critical challenge for establishing healthy cities. In this regard, Duhl and Sanchez (1999) defined a list of six fundamental characteristics (Health public policy, Innovation, Community participation, Intersectoral action, Policy decision making and Commitment to health) that would be needed to create a healthy city. If these characteristics are adopted, it is likely that a healthy city will emerge. Thus, this framework suggests that by utilising a DSS as part of a broader healthy cities planning process, it is more likely that healthy community will be established.

One of the innovative ways to present, store, analyse and manipulate information for local decision-making is by adding a spatial aspect, particularly given that social determinants of health are spatially oriented (i.e., grounded in place). In this regard, health information could be geo-coded (into Geographical Information Systems [GIS] software) and displayed spatially, so end-users can create maps by using different layers of spatial information overlaid on each other. This method provides a new way of looking at health concerns and may lead to new decision-making. Thus, application of spatial technologies is an important step towards a better understanding of public health issues and their inherent complexities and for gaining insight into the spatial distribution of health determinants (Higgs \& Gould, 2001). However, it is essential to expand the use of this tool through online platforms or as part of broader e-health initiatives.

For example, for decision-makers to identify gaps in the provision of health facilities in a given community, GIS could be utilised to examine the effect of travel time to health facilities by mapping catchment areas and travel zones. The impact of new facilities or new transport routes can be examined in hypothetical scenarios. By placing this information in an online setting, the capacity to share information in a variety of forms will improve stakeholders' involvement in decision-making, horizontal knowledge sharing and simplicity of the decision process (Dur, Yigitcanlar \& Bunker 2009). Testing this framework in a real case-study would ascertain whether the DSS has a valuable impact on health planners.

\section{CASE STUDY: THE LOGAN- BEAUDESERT HEALTH COALITION}

The Logan Beaudesert Health Coalition (LBHC) is a partnership established to address the growing level of chronic disease in the region. The initiative intended to build on work that had preceded it, enhancing existing services and infrastructure, establishing formal partnerships and mechanisms to improve the coordination of existing resources as well as planning for additional services and strategies. It was initiated with a view to improving health capacity at multiple levels through improved and responsive localised planning. The Coalition has a central board committee which oversees six health initiatives or working groups, each focusing on a specific area identified as needing attention. These working groups focus on the early years of life ( 0 to 8 years), multicultural health, prevention and management of existing chronic disease, integration between general practice and acute settings, efficient management and transfer of health information and health promotion. Each group has a leader or project manager and a selected group of key stakeholders from multiple sectors or relevant organisations. The working groups are responsible for facilitating decisions, polices or strategies by providing recommendations and information to the LBHC board. The LBHC board coordinates and directs the coalition as a 'whole'. Thus, given its focus on collaborative decision-making, the LBHC is an ideal platform from which to develop and observe the DSS and its potential role.

\section{METHOD}

The purpose of this study was to understand the potential role of the DSS in improving the collaborative health planning practice of the LBHC. Both quantitative and qualitative data were collected prior to the implementation of the DSS to explore the decision-making strategies and experiences of the coalition members. The quantitative data was collected using a 31-item survey based on several decision-making scales (Dean \& Sharfman, 1993; Flood et al, 2000; Bennet et al, 2010; Parnell \& Bell, 1994). The items measured the following four dimensions of decision-making outlined by Murray (2006): Evidence-based decision-making (5 items); Perceived consensus (4 items); Participation in 
decision-making (3 items) and Perceived satisfaction of decision-making (10 items), defined as our four key variables. In addition, three process variables were measured, including: Perceived importance of decision-making (3 items); Perceived effectiveness of decision-making (3 items); and Perceived equity of decision-making (3 items). Forty participants were required to rate the extent to which they agreed with each item using a 7 point Likert scale, with choices ranging from 'not at all' to 'completely agree'. The questionnaire was disseminated to the members of LBHC both in 'hard copy' and an online survey so that the participants could select their preferred method of completion. Participants were also asked to comment on their decision-making processes and experiences within the LBHC to provide context for the quantitative findings. Both the quantitative and qualitative data will be collected again once the DSS has been fully implemented, thus allowing an evaluation of the implementation process and DSS utility.

\section{PRELIMINARY FINDINGS}

Table 1 provides the descriptive statistics for each of the decision-making domains. The findings indicate that, overall, satisfaction with information for decision-making and perceived effectiveness of decision-making were rated lowest of the seven domains. Conversely, perceived participation of decision-making and perceived equity of decisionmaking were rated highest. To further examine Murray's (2006) four domains, one way Analysis of Variance (ANOVA) and Post Hoc tests were conducted using different groups within the LBHC as independent variables. Participants were first divided into clusters representing the different types of initiatives that were auspiced by the LBHC. Three clusters were constructed to represent a focus on governance (the board and administration), health promotion (the Early Years Team, Health Promotion scholars and the Multicultural Initiative) and disease management/service integration (the GP Liaison team, Information Management Initiative and Optimal Health Team). A One Way ANOVA test showed that consensus and participation tended to be higher for the board than the other teams, but the differences were not significant.

Participants were then grouped into two major age groups: 1) 0-40; 2) 40+. A One Way ANOVA revealed a significance difference in the accumulated means for the following variables, participation, consensus and satisfaction with information.

Table 1: Means, Standard Deviations and Frequencies of Responses to the 7 Domains of Decision-Making

\begin{tabular}{|c|c|c|c|c|c|c|c|c|c|}
\hline Dimension & Mean & $\begin{array}{l}\text { Standard } \\
\text { deviation }\end{array}$ & Not at all & A Little & Some & Moderately & Often & Mostly & Completely \\
\hline $\begin{array}{l}\text { Perceived evidence- } \\
\text { based decision-making }\end{array}$ & 4.33 & 2.18 & $\begin{array}{l}3 \\
(1.8 \%)\end{array}$ & $\begin{array}{l}18 \\
(11.0 \%)\end{array}$ & $27(16.6 \%)$ & $\begin{array}{l}40 \\
(24.5 \%)\end{array}$ & $\begin{array}{l}32 \\
(19.6 \\
\%)\end{array}$ & $\begin{array}{l}35 \\
(21.5 \%)\end{array}$ & $\begin{array}{l}8 \\
(4.9 \%)\end{array}$ \\
\hline $\begin{array}{l}\text { Perceived consensus of } \\
\text { decision-making }\end{array}$ & 4.55 & 2.24 & $\begin{array}{l}4 \\
(3.2 \%)\end{array}$ & $\begin{array}{l}14 \\
(11.1 \%)\end{array}$ & $\begin{array}{l}17 \\
(13.5 \%)\end{array}$ & $\begin{array}{l}27 \\
(21.4 \%)\end{array}$ & $\begin{array}{l}18 \\
(14.3 \\
\%)\end{array}$ & $\begin{array}{l}29 \\
(23.0 \%)\end{array}$ & $\begin{array}{l}17 \\
(13.5 \%)\end{array}$ \\
\hline $\begin{array}{l}\text { Perceived participation } \\
\text { in decision-making }\end{array}$ & 4.80 & 2.32 & $\begin{array}{l}4 \\
(3.8 \%)\end{array}$ & $\begin{array}{l}9 \\
(8.7 \%)\end{array}$ & $\begin{array}{l}14 \\
(13.5 \%)\end{array}$ & $\begin{array}{l}14 \\
(13.5 \%)\end{array}$ & $\begin{array}{l}20 \\
(19.2 \\
\%)\end{array}$ & $\begin{array}{l}21 \\
(20.2 \%)\end{array}$ & $\begin{array}{l}22 \\
(21.2 \%)\end{array}$ \\
\hline $\begin{array}{l}\text { Perceived satisfaction } \\
\text { with information for } \\
\text { decision-making }\end{array}$ & 3.49 & 2.22 & $\begin{array}{l}50 \\
(14.9 \%)\end{array}$ & $\begin{array}{l}55 \\
(16.4 \%)\end{array}$ & $\begin{array}{l}68 \\
(20.3 \%)\end{array}$ & $\begin{array}{l}55 \\
(16.4 \%)\end{array}$ & $\begin{array}{l}56 \\
(16.7 \\
\%)\end{array}$ & $\begin{array}{l}50 \\
(14.9 \%)\end{array}$ & $\begin{array}{l}1 \\
(.3 \%)\end{array}$ \\
\hline $\begin{array}{l}\text { Perceived importance of } \\
\text { decision-making }\end{array}$ & 4.63 & 2.27 & $\begin{array}{l}0 \\
(0 \%)\end{array}$ & $\begin{array}{l}9 \\
(9.2 \%)\end{array}$ & $\begin{array}{l}23 \\
(23.5 \%)\end{array}$ & $\begin{array}{l}17 \\
(17.3 \%)\end{array}$ & $\begin{array}{l}10 \\
(10.2 \\
\%)\end{array}$ & $\begin{array}{l}24 \\
(24.5 \%)\end{array}$ & $\begin{array}{l}15 \\
(15.3 \%)\end{array}$ \\
\hline $\begin{array}{l}\text { Perceived equity of } \\
\text { decision-making }\end{array}$ & 4.77 & 2.31 & $\begin{array}{l}6 \\
(7.2 \%)\end{array}$ & $\begin{array}{l}3 \\
(3.6 \%)\end{array}$ & $\begin{array}{l}6 \\
(7.2 \%)\end{array}$ & $\begin{array}{l}9 \\
(10.8 \%)\end{array}$ & $\begin{array}{l}30 \\
(36.1 \\
\%)\end{array}$ & $\begin{array}{l}23 \\
(27.7 \%)\end{array}$ & $\begin{array}{l}6 \\
(7.2 \%)\end{array}$ \\
\hline $\begin{array}{l}\text { Perceived effectiveness } \\
\text { of decision-making }\end{array}$ & 3.83 & 2.26 & $\begin{array}{l}8 \\
(8.2 \%)\end{array}$ & $\begin{array}{l}13 \\
(13.4 \%)\end{array}$ & $\begin{array}{l}16 \\
(16.5 \%)\end{array}$ & $\begin{array}{l}24 \\
(24.7 \%)\end{array}$ & $\begin{array}{l}17 \\
(17.5 \\
\%)\end{array}$ & $\begin{array}{l}18 \\
(18.6 \%)\end{array}$ & $\begin{array}{l}1 \\
(1.0 \%)\end{array}$ \\
\hline
\end{tabular}


Table 2: Comparison of selected four key variables with LBHC major age groups

\begin{tabular}{|c|c|c|c|c|}
\hline $\begin{array}{l}\text { LBHC Affiliation by two } \\
\text { major groups }\end{array}$ & $\begin{array}{l}\text { Perceived evidence-based } \\
\text { decision-making }\end{array}$ & $\begin{array}{l}\text { Perceived consensus of } \\
\text { decision-making }\end{array}$ & $\begin{array}{l}\text { Perceived participation } \\
\text { of decision-making }\end{array}$ & $\begin{array}{l}\text { Perceived satisfaction } \\
\text { with information of } \\
\text { decision-making }\end{array}$ \\
\hline $0-40$ - young & $\begin{array}{l}\text { Mean }=3.9 \\
\text { Std. Deviation = } 1.1 \\
\mathrm{~N}=11\end{array}$ & $\begin{array}{l}\text { Mean }=3.6 \\
\text { Std. Deviation = } 1.4 \\
\mathrm{~N}=11\end{array}$ & $\begin{array}{l}\text { Mean }=3.7 \\
\text { Std. Deviation = } 1.1 \\
\mathrm{~N}=11\end{array}$ & $\begin{array}{l}\text { Mean }=2.3 \\
\text { Std. Deviation = } 1.5 \\
\mathrm{~N}=10\end{array}$ \\
\hline $40+$ veterans & $\begin{array}{l}\text { Mean }=4.7 \\
\text { Std. Deviation = } 0.8 \\
\mathrm{~N}=13\end{array}$ & $\begin{array}{l}\text { Mean }=5.0 \\
\text { Std. Deviation }=1.2 \\
\mathrm{~N}=13\end{array}$ & $\begin{array}{l}\text { Mean = 5.4 } \\
\text { Std. Deviation = } 1.4 \\
\mathrm{~N}=14\end{array}$ & $\begin{array}{l}\text { Mean }=4.5 \\
\text { Std. Deviation = } 1.3 \\
\mathrm{~N}=13\end{array}$ \\
\hline Statistics details & $\begin{array}{l}\mathrm{DF}=1 \\
\mathrm{~F}=3.7 \\
\mathrm{SIG}=.066 \\
\text { *non-significant(trended } \\
\text { towards significant) }\end{array}$ & $\begin{array}{l}\mathrm{DF}=1 \\
\mathrm{~F}=5.9 \\
\mathrm{SIG}=.02 \\
* \text { significant }\end{array}$ & $\begin{array}{l}\mathrm{DF}=1 \\
\mathrm{~F}=9.6 \\
\mathrm{SIG}=.005 \\
* \text { significant }\end{array}$ & $\begin{array}{l}\mathrm{DF}=1 \\
\mathrm{~F}=13.8 \\
\mathrm{SIG}=.002 \\
\text { * significant }\end{array}$ \\
\hline
\end{tabular}

Evidence-based decision-making showed a trend towards significance (see Table 2). Specifically, the younger age group reported lower scores on all four key variables.

When grouped according to their duration of membership in the LBHC, no significant differences were found on any variables. The tenure groups were constructed as follows: those who were new to the LBHC (less than 12 months), intermediate members (12-24 months) and veterans (more than 24 months). One Way ANOVA showed no significant difference in the accumulated means. However, new members and the veterans tended to report higher scores than the intermediate age group. We then tested the difference between accumulated means on our four key variables across gender groups, with no significant differences. Males tended to report higher scores than females, but only represented $30 \%$ of our sample.

The qualitative data provided by members revealed further detail that might explain the quantitative findings. For instance, one participant noted that, 'Very few decisions have ever been made by the Board - most decisions are made by a few outside the meeting, and therefore there is no rigour or transparency to the processes'. Another participant commented on the relative absence of decision-making: 'I'm not sure if any actual planning for the future is made, with the exception of recent 'planning sessions'. The lack of control over decisions made by the coalition was a recurrent theme in the qualitative comments; 'I thought a decision had been made prior to our input'.

However, the majority of comments made by coalition members revealed the difficulty associated with making decisions in the absence of adequate information.

'[We] need to identify priority actions, need to be more pro-evidence in our decision making'.

'There is a serious lack of information and communication [to guide decision-making] '

The value of evidence-based decisions was clear throughout the data; 'If the LBHC goes down the pathway of prioritising strategic directions based on evidence, inclusive decision making processes (including community input), this will have great potential to more appropriately address [the] issues'.

Despite high scores on consensus and participation, some members noted that problems existed in relation to the sense of connectedness of the coalition "as a whole" and that this had a significant impact on decision-making.

\section{DISCUSSION AND FUTURE RESEARCH}

The preliminary quantitative and qualitative findings of this study confirm that overall there were low levels of satisfaction with the decision-making processes across the LBHC. However, some groups 
within the LBHC were more satisfied than others (i.e., those who were over 40 years). There was also a tendency for LBHC board members, males, new members and veterans to be more satisfied with information and perceive higher levels of consensus, participation and evidence-based decision-making. The data suggested that the lack of satisfaction with information for decision-making may be due to the complete lack of evidence on which to base decisions. This lack of evidence seemed to contribute to a sense of disconnectedness between the different elements of the LBHC. For example, some elements in the LBHC perceived that the decision-making processes were not being practiced consensually and in a participatory manner. The data indicated that within some groups (i.e., Board), there were high levels of consensus and participation, but that this may not occur across the whole LBHC. Further, there was an overall sense that decisions were ineffective, presumably because they were not based on information or evidence.

Although not significant, there was some diversity across the components of the LBHC. Males tended to be more satisfied as did those who had been members of the LBHC for either longer or shorter periods. This finding indicates the likelihood of an acculturation curve for members (i.e., new members are enthusiastic, but become more critical of decision-making over time and then eventually resolve this situation in some way - either by withdrawing or seeking other sources of information). Age of members had an important influence on the way decision-making was

\section{ACKNOWLEDGEMENTS}

This study is part of a broader ARC project named: Coalitions for Community Health: A Community-based Response to Chronic Disease. The

\section{REFERENCES}

Bennett, C, Graham, ID, Kristjansson, E, Kearing, SA, Clay, KF \& O'Connor, AM (2010) Validation of a Preparation for Decision Making Scale. Patient Education and Counseling 78: 130-133 Elsevier.

Bishop, P. and Davis, G. (2001). Developing consent consultation, participation and governance. In Are You Being Served? Eds. G. Davis and P. Weller. Sydney, Allen \& Unwin: 175-195.

Campbell, S. and Fainstein, S.S. (1996). Introduction: the structure and debates of planning theory. In Readings perceived. It is possible that younger people could be more demanding in terms of their need for involvement in the decision-making processes, whereas veterans are likely to have access to more intrinsic sources of information based on years of experience in the region. As a result, they may be less demanding of the decision-making processes. As for the variation across the LBHC, the tendency towards significant differences between the subgroups of the LBHC indicates that there may be considerable diversity in decision-making that may require different approaches to planning.

In summary, our findings have shown that there is some diversity in the way members of a LBHC view decision-making. They have also highlighted the need for a comprehensive information framework and collaborative process to underpin planning for healthy cities, thus enabling health coalitions to make effective decisions that engage all stakeholders equitably. The framework proposed in this paper would not only encourage planners to engage with evidence and information about the entire range of health determinants, but would also provide a platform for collaboration and shared engagement in the decision-making process. Questions about how the framework and method are actually applied in local communities, the impact of the DSS on decision-making and its ability to facilitate collaborative-based health planning, remain unanswered and form the basis of this ongoing research. These important research questions will be addressed in the near future.

authors would like to acknowledge the investigators of this project, Elizabeth Kendall, Scott Baum, Heidi Muenchberger and Tan Yigitcanlar.

in urban theory, Eds. S. Campbell and S.S. Fainstein Oxford, Blackwell Publishing:1-16.

Cromley, E.K. and McLafferty, S.L. (2003). GIS and public health. Health \& Place 9(3): 279.

Dean JR, JW and Sharfman, M.P. (1993). Procedural rationality in the strategic decision-making process. Journal of Management Studies 30(4): 587-609.

Duhl, L. J., \& Sanchez, A. K. (1999). Healthy cities and the city planning process. A Background Documentation On Links Between Health And Urban 
Planning, Copenhagen, WHO, Regional Office For Europe.

Dur, F., Yigitcanlar, T. and Bunker, J. (2009). A decision support system for sustainable urban development: the integrated land use and transportation indexing model. Proceedings of the Postgraduate Infrastructure Conference. Brisbane, Australia, 26 March. Queensland University of Technology.

Flood, P., Hannan, E., Smith, K., Turner, T., West, M., \& Dawson, J. (2000). Chief executive leadership style, consensus decision making, and top management team effectiveness. European Journal of Work \& Organizational Psychology 9(3), 401-420.

Flynn, B.C. (1996). Healthy cities: toward worldwide health promotion. Annual Review of Public Health 17: 299-309.

Gudes, O., Kendall, E., Yigitcanlar, T., Pathak, V. and Baum, S. (2010). Rethinking health planning: a framework for organising information to underpin collaborative health planning. Health Information Management Journal 39 (2): 18-29.

Han J.H., Kendall, E., Sunderland, N., Gudes, O. and Henniker, G. (2010) Chronic disease, geographic location and socioeconomic disadvantage as obstacles to equitable access to e-health. Health Information Management Journal 39 (2): 30-36.

Healthy Cities Illawarra (2010). Working with the community for a healthier, safer, greener and more caring Illawarra. Wollongong: Illawarra city council. Available http://www.healthycitiesill.org.au/contactus.htm (Accessed 10 October 2010).

Higgs, G. and Gould, M. (2001). Is there a role GIS in the 'new NHS'? Health \& Place 7(3): 247-59.

Mooney, G. and Fohtung, N.G. (2008). Issues in the measurement of social determinants of health. Health Information Management Journal 37(3): 26-30.

Murray, D.J. (2006). A critical analysis of communicative planning theory as a theoretical underpinning for integrated resource and environmental management. Unpublished PhD thesis, Griffith University, Queensland.
National Electronic Decision Support Taskforce. (2008). Electronic Decision Support Systems Report. Department of Health and Ageing. Canberra: Australia.

NHHRC (2009). A healthier future for all Australians. Canberra, ACT, National Health and Hospitals Reform Commission.

Northridge, M.E., Sclar, E.D. and Biswas, P. (2003). Sorting out the connections between the built environment and health: a conceptual framework for navigating pathways and planning healthy cities. Journal of Urban Health 80(4): 556-568.

Parnell, J. A. and Bell, E. D. (1994). 'The propensity for participative decision making scale: A measure of managerial propensity for participative decision making.' Administration \& Society 25(4): 518-533.

Reeves, P.N. and Coile, R.C (1989). Introduction to health planning. Arlington, VA: Information Resources Press.

Reinke, W.A. (1972). Health planning: qualitative aspects and quantitative techniques. Baltimore, MD: Johns Hopkins University School of Hygiene and Public Health, Department of Internet Health.

Schulz, A. and Northridge, M.E. (2004). Social determinants of health: implications for environmental health promotion. Health Education \& Behaviour 31(4): 455-471.

Turban, E. (1993). Decision support and expert systems: management support systems: Prentice Hall PTR Upper Saddle River, NJ, USA.

Wave, V. (2009). mHealth for development: the opportunity of mobile technology for healthcare in the developing. United Nations Foundation and Vodafone Foundation.

WHO (1997). Twenty steps for developing a healthy cities project. WHO Regional Office of Europe.

WHO (1999). Health: creating healthy cities in the $21 \mathrm{st}$ century. In The Earthscan reader in sustainable cities. Ed. D, Satterthwaite. London, Earthscan: 137-172.

WHO (2010). Urban health Healthy Cities. Available at: http://www.euro.who.int/en/what-we-do/healthtopics/environmental-health/urbanhealth/activities/healthy-cities (Accessed 9 October 2010). 
Appendix: A conceptual framework for planning a healthy city (Modified after World Health Organization 1997; Schulz \& Northridge 2004).

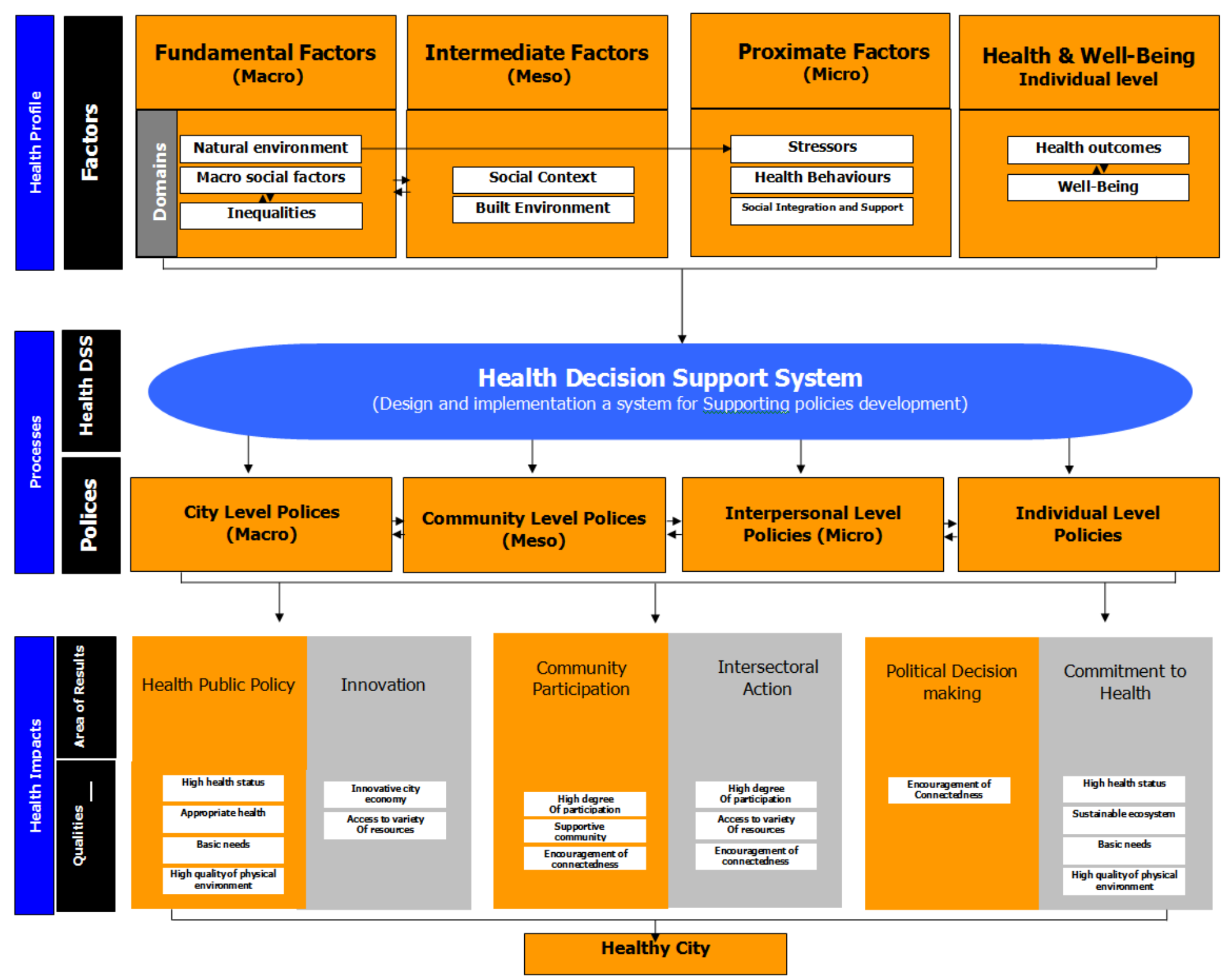

